\title{
EVOLUCIÓN DEL SERVICIO DIPLOMÁTICO Y CONSULAR DEL PARAGUAY Y SU SISTEMA JURÍDICO
}

\section{EVOLUCÃO DO SERVICO DIPLOMÁTICO E CONSULAR DO PARAGUAI E SEU SISTEMA JURÍDICO}

\section{Liz Haydee Coronel Correa}

Resumen: Si bien la República del Paraguay ha tenido una activa vida diplomática desde sus orígenes, la carrera de servicio público destinada a velar por sus intereses en el exterior es relativamente nueva, a diferencia de los otros Estados fundadores del MERCOSUR, cuyas leyes del Servicio Exterior datan de, por lo menos, 30 años.

En este artículo se resume la historia de la institucionalización de este Servicio en el Paraguay, que no ha podido iniciarse con pie firme hasta el año 1999. A partir de entonces, los gobiernos sucesivos han respetado este proceso; esto ha permitido que la construcción de un Servicio Diplomático y Consular profesional e independiente de factores políticos pueda cobrar fuerza y estabilidad, para contribuir a la consolidación de una institucionalidad regional.

Resumo: Embora que a República do Paraguai ha tido uma ativa vida diplomática desde suas origens, a carreira de serviço público destinado a velar pelos interesses no exterior e relativamente nova, a diferença de outros Estados fundadores do MERCOSUR, cujas leis do serviço exterior têm pelos menos 30 anos.

Neste artigo se resume história da institucionalização deste Serviço no Paraguai, que não ha podido iniciar-se com pé firme até o ano 1999. A partir de então, os governos sucessivos respeitam dito processo; isto há permitido que a construção de um serviço diplomático e consular profissional e independente de fatores políticos possa adquirir forca e estabilidade, para contribuir á consolidação de uma institucionalidade regional.

Palabras clave: Servicio Diplomático y Consular, Paraguay, Escalafón, Carrera

* Ministerio de Relaciones Exteriores, Paraguay.

E-mail: lhcc@mre.gov.py

Recibido: 2/02/2017. Aceptado: 10/03/2017. 
Palavras-chave: Serviço Diplomático e Consular, Paraguai, Hierarquia, Carreira

\section{INTRODUCCIÓN}

El Servicio Diplomático y Consular (SDC) de un país es su herramienta para la ejecución de su política internacional, así como para la protección de los intereses del Estado y de sus connacionales en el exterior. En el contexto del MERCOSUR, los Estados Miembros se relacionan entre sí a nivel oficial primariamente a través de sus respectivas Cancillerías, y de sus respectivos SDC, que ejercen la función de articuladores de las políticas públicas entre los órganos del Estado y el exterior. Estos Servicios consuetudinariamente están constituidos como cuerpos de funcionarios públicos permanentes, profesionalmente capacitados y organizados en carrera administrativa, con categorías jerarquizadas, dentro de los Ministerios de Relaciones Exteriores.

Paraguay ha buscado sistematizar su Servicio Diplomático y Consular desde el año 1946, incluso antes de la adopción de las Convenciones de Viena. Sin embargo, tras varios intentos legislativos que no han tenido una continuidad en el tiempo, esto ha sido posible recién a partir de la promulgación de la Ley No 1335 del Servicio Diplomático y Consular, en el año 1999.

La Constitución paraguaya, promulgada en 1992, establece en su Artículo 101 que la ley reglamentará las carreras a través de las cuales los funcionarios y empleados públicos prestarán servicio al país y menciona, taxativamente, la judicial, la docente, la diplomática y consular, la de investigación científica y tecnológica, la de servicio civil, la militar y la policial; es bajo el amparo de este precepto constitucional que se promulga la Ley No 1335/99 que establece la carrera como de servicio público civil y reglamenta su organización, funciones, derechos y obligaciones. Actualmente un $42,5 \%$ del funcionariado permanente del Ministerio de Relaciones Exteriores del Paraguay está dentro del Escalafón Diplomático y Consular, que es la ordenación jerárquica del Servicio.

\section{ANTECEDENTES DE LA CARRERA DIPLOMÁTICA Y CONSULAR}

Si bien la diplomacia internacional ya era una profesión con un orden jerárquico claro, y con un código bien establecido a mediados del 1800, en Paraguay se registran antecedentes de un intento de profesionalización y de la creación de un marco legal para dicho oficio recién en el año 1941, con el Decreto-Ley No 6430 que aprueba el estatuto 
orgánico del Ministerio de Relaciones Exteriores y Culto.

Este documento fue sustituido por el Decreto-Ley No 14757, del 24 de julio de 1946. En él, el Presidente de la República ${ }^{1}$ decreta con fuerza de ley un Estatuto por el que debe regirse el personal del Ministerio de Relaciones y Culto, que comprende "a) el personal del cuadro permanente del Servicio Exterior de la nación; b) el personal administrativo y técnicoprofesional; c) el personal de servicio." y el personal del Clero, incluso el administrativo y de servicio que de él dependen.

En su Art. $3^{\circ}$ establece la clasificación jerárquica del personal del Servicio Exterior, en las siguientes categorías:

a) embajadores extraordinarios y plenipotenciarios;

b) enviados extraordinarios y ministros plenipotenciarios;

c) consejeros de embajadas, y cónsules generales de primera clase;

d) consejeros de legaciones, y cónsules generales de segunda clase;

e) secretarios de primera clase y cónsules de primera clase;

f) secretarios de segunda clase y cónsules de segunda clase;

g) Adictos y vicecónsules

En el mismo artículo se señala que los funcionarios de las dos primeras jerarquías deben tener no menos de treinta años; y los demás deben ser mayores de edad.

En este extenso Decreto-Ley de 106 artículos, se regula la carrera diplomática en cuanto al ingreso exclusivamente en el rango de secretario de legación de $2^{\text {a }}$ clase, así como la provisión de vacancias y nombramientos, estableciéndose para el efecto un Tribunal de Calificaciones y de Disciplina compuesto de cinco miembros elegidos entre exministros de Estado, preferentemente exministros de Relaciones Exteriores y Culto, exministros plenipotenciarios y profesores universitarios.

En el capítulo de Rotación y Traslados, se dispone que "el periodo de servicios en la Cancillería no deberá exceder de cuatro años continuados" pero exime de este plazo al sub-secretario, al secretario general y a los funcionarios que por su notoria especialización deban permanecer en sus respectivos cargos, a juicio del ministro. Asimismo, establece que "el periodo de servicios en el exterior no podrá comportar una permanencia de más de seis años consecutivos en el mismo país" pero abre un resquicio para los Jefes de Misión quienes quedarán exentos mediante Decreto del Poder Ejecutivo.

Además de listar los deberes y atribuciones, así como las prohibiciones de los funcionarios diplomáticos en general, se detiene en cada una de las categorías del Servicio Exterior para exponer en detalle sus deberes y atribuciones, incluyendo los de los Agregados Militares,

1 Presidente de la República: Higinio Morínigo. Ministro de Relaciones Exteriores: Antonio Taboada 
quienes también forman parte del servicio diplomático, en virtud de este Decreto Ley.

En cuanto a la estabilidad de los funcionarios del Servicio Exterior ${ }^{2}$, este documento se extiende en detallar las causales de remoción, penas disciplinarias y la declaración de disponibilidad; así también, consagra el derecho a la jubilación, en su carácter de empleado público, y dispone con precisión el mecanismo de asignación de sueldos, gastos de representación, de instalación y otros beneficios inherentes a la función.

Este Decreto-Ley dedica un detallado capítulo a los deberes y atribuciones de los Cónsules que deben formar parte del Servicio; finalmente, dispone la organización de una Comisión Asesora Permanente, que estaba compuesta -además de representantes del MRE- por representantes de los Ministerios de Hacienda, Agricultura, Industria y Comercio, Banco de la República y el sector privado, y que tenía a su cargo el estudio y las negociaciones comerciales con los países extranjeros; así como una Comisión de Cooperación Intelectual constituida por representantes del MRE, de la Universidad Nacional de Asunción y otras instituciones culturales y científicas.

Pero tan completa normativa no había tenido el aval parlamentario, y no había sido sostenidamente implementada, por lo que en $1967^{3}$, a instancias del entonces canciller Raúl Sapena Pastor y de los diplomáticos en servicio activo de la época, el Poder Ejecutivo sometió a consideración de la Cámara de Representantes un proyecto para reglamentar la actividad diplomática e iniciar la capacitación para una carrera especializada. La iniciativa mereció el dictamen favorable del mencionado cuerpo legislativo.

Como resultado de esa gestión, en el mes de noviembre del año 1970 fue promulgada la Ley No 219 "Que crea la Carrera Diplomática y Consular", estableciéndose en su artículo $1^{\circ}$ que esta se creaba como función especializada al servicio de las relaciones internacionales de la República. La ley divide al personal del Ministerio de Relaciones Exteriores en tres categorías, similares a las del Decreto-Ley No 14757 , pero omite la categoría de "personal de servicio".

Por primera vez, en esta ley se utiliza la palabra "Escalafón" para señalar el marco de la agrupación del personal del Servicio Diplomático y Consular del Ministerio de Relaciones Exteriores, señalando que " $\mathrm{La}$ 'Carrera Diplomática y Consular' tiene por objeto agrupar, dentro de un Escalafón, del servicio diplomático y consular del Ministerio de Relaciones Exteriores, clasificándolo en razón de grados, antigüedad y méritos".

Establece dicho Escalafón, con los siguientes grados:

a) Adicto y Vice-cónsul;

b) Segundo Secretario y Cónsul de Segunda clase;

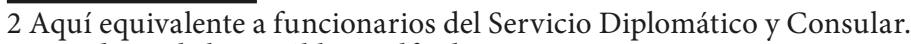

3 Presidente de la República: Alfredo Stroessner. 
c) Primer Secretario y Cónsul de Primera clase;

d) Consejero y Cónsul General;

e) Ministro;

f) Embajador.

Si bien es una Ley con tan sólo 20 artículos de fondo, establece importantes principios como la precedencia dentro de cada grado, basada en la antigüedad y en los méritos, la posibilidad de desempeñar funciones indistintamente tanto en el exterior como en la sede del Ministerio de Relaciones Exteriores, y la preferencia del desempeño de funciones diplomáticas y consulares para los funcionarios escalafonados, salvo que no existieran funcionarios de carrera en el grado correspondiente al cargo o por circunstancias especiales que requieran utilizar los servicios de personas ajenas al Escalafón. Se establecen los requisitos esenciales para pertenecer al Escalafón, muy similares a los ya establecidos en el Decreto-Ley No 14757, y se dispone que el ingreso al mismo deberá ser con el grado de Adicto o Vice-Cónsul.

Un importante hito marcado por esta ley es la creación de la Academia Diplomática y Consular, como unidad dependiente del Ministerio de Relaciones Exteriores, con la finalidad de capacitar y perfeccionar a los funcionarios del Escalafón. Además, se abre la posibilidad de tomar cursos y convalidar las materias de universidades nacionales con las correspondientes al plan de estudios de la Academia y se incentiva al estudio de idiomas.

Se establece la designación de un Tribunal de Calificaciones y Disciplina, que sería presidido por el Ministro de Relaciones Exteriores y cinco miembros expertos en derecho internacional y diplomático, y se señala que su parecer es indispensable para la incorporación y ascensos en el Escalafón. Finalmente, se determina que el Poder Ejecutivo dictará los reglamentos para la organización y el funcionamiento de la Carrera Diplomática y Consular, la Academia Diplomática y Consular y el Tribunal de Calificaciones y Disciplina.

Posteriormente, en febrero de 1972, fue promulgado el Decreto No $24450^{4}$ que reglamenta la Ley No 219 de 1970, basándose en su Artículo 17 que dispone que el Poder Ejecutivo dictará los Reglamentos para la organización y funcionamiento de la "Carrera Diplomática y Consular", de la "Academia Diplomática y Consular" y del "Tribunal de Calificaciones y Disciplina”.

Este Decreto complementa a la ley, estableciendo que la "Carrera Diplomática y Consular, como carrera especializada al servicio de las relaciones internacionales de la República, tiene por finalidad la formación de un 'Escalafón' de funcionarios capacitados cuyos servicios serán utilizados por el Ministerio de Relaciones Exteriores, tanto en

4 Siendo Canciller Nacional el Doctor Raúl Sapena Pastor. 
la Cancillería Nacional, como en el Servicio Exterior Diplomático y Consular", así también define el "Escalafón Diplomático y Consular", determina cómo se establecerán la precedencia, la antigüedad, el ingreso y los ascensos en el Escalafón, y reitera algunas disposiciones ya presentes en la ley, pero con más detalle.

Por otra parte, reglamenta el funcionamiento de la Academia Diplomática y Consular, el Plan de Estudios, de los cursos que se impartirán en la misma y contempla previsiones para su funcionamiento antes de contar con previsión presupuestaria. Finalmente, establece las funciones del Tribunal de Calificaciones y Disciplina, en consonancia con el Artículo 15 de la Ley No 219 de 1970.

Esta legislación se mantuvo vigente, con dispar aplicación, hasta la promulgación de la Ley No 1335, el 2 de marzo de 1999 -que deroga la Ley No 219 de 1970 y el Decreto-Ley No 14757-, y de la aprobación del primer Escalafón del Servicio Diplomático y Consular de la República del Paraguay, por Decreto No 6847 de fecha 22 de diciembre de 1999.

Un dato no menor que resaltar es que este hito histórico en la Política Exterior paraguaya se dio en un año particularmente convulsionado políticamente; 1999 fue el año del "marzo paraguayo" ocasionado por el asesinato del entonces Vicepresidente Luis María Argaña (coincidentemente también ex Canciller de la República), por lo que esta ley fue una de las últimas promulgadas por el Presidente Raúl Cubas Grau y su Ministro de Relaciones Exteriores, Dido Florentín Bogado. El 28 de marzo asume la Presidencia Luis Ángel González Macchi (Partido Colorado) y, como resultado del "Gobierno de Unidad Nacional", es nombrado Ministro de Relaciones Exteriores Miguel Abdón Saguier (Partido Liberal Radical Auténtico), quien permanece al frente de la Cancillería Nacional hasta el 4 de setiembre de ese año, cuando lo reemplaza José Félix Fernández Estigarribia, bajo cuyo mandato se reciben las carpetas de los funcionarios que deseen formar parte del primer Escalafón. Una vez vencido el plazo de presentación de solicitudes y habiendo estudiado las carpetas presentadas, el 22 de diciembre de 1999 es emitido el Decreto que daría inicio a la sistematización de la Carrera Diplomática y Consular paraguaya. Así, la ley y el decreto aparecen con una diferencia de 9 meses y habiéndose ocupado del tema 3 Cancilleres, dentro de un mismo año.

Otro hecho resaltante en la historia reciente de este Servicio Diplomático y Consular es que la Ley No 1335 de 1999 fue numerosas veces atacada judicialmente, particularmente el artículo 56 de las Disposiciones Transitorias en el que se disponía la incorporación por única vez al Escalafón a los funcionarios que ya estén prestando servicios en la Cancillería o en el exterior, en base a criterios previstos en los incisos a) al f). Varias acciones de inconstitucionalidad fueron dirigidas contra los incisos a) y b) por considerárselos discriminatorios. 
La diferenciación de "dos años en el exterior" o "cuatro años en la República" (para los que poseyeran título universitario, y un periodo más amplio pero igualmente diferenciado para los que no lo tuvieran) para la incorporación al Escalafón constituyó una de las puertas de entrada a las acciones judiciales, tanto ante el Tribunal de Cuentas como de la Corte Suprema de Justicia, que impidieron el cumplimiento de lo establecido en dicho artículo 56.

Así, a lo largo de estos 17 años, incluso luego del inicio de los Concursos de Oposición y Méritos en el año 2007, las sentencias judiciales hicieron posible la incorporación o recategorización de miembros al Escalafón Diplomático y Consular. Por esta vía se incorporaron 117 funcionarios: 2 embajadores, 1 ministro, 6 consejeros, 17 primeros secretarios, 23 segundos secretarios y 68 terceros secretarios.

\section{ACADEMIA DIPLOMÁTICA Y CONSULAR}

Sobre la capacitación de los diplomáticos paraguayos, es importante resaltar que una vez promulgada la Ley No 219 de 1970, el Ministerio de Relaciones Exteriores inició el proceso de organización de una Academia para capacitar a sus cuadros, con una malla curricular que incorporaba asignaturas teóricas y prácticas para los futuros funcionarios del Servicio Exterior y para aquellos que ya estaban en el ejercicio de cargos diplomáticos y consulares en el extranjero. Mediante el Decreto No 24450 antes mencionado se iniciaron los cursos de: Redacción y Estilo, Criptotécnica, Idioma Guaraní, Síntesis de Derecho Civil, Comercial y Constitucional, Historia Diplomática del Paraguay, Geopolítica y Orientación de la Política Exterior Nacional. Ese mismo año, y en virtud del mismo decreto, se creó la Junta de Calificaciones y Disciplina del Ministerio de Relaciones Exteriores. En 1973 se dictaron asignaturas que guardaban relación con los rangos diplomáticos, a saber:

Para el rango de Adicto y Vicecónsul: Práctica en Dactilografía, Práctica Criptográfica, Práctica de Documentos y Archivo, Redacción y Estilo de Notas y Derecho Diplomático y Consular (primera parte).

Para el rango de Segundo Secretario y Cónsules de Segunda Clase: Inglés, Práctica Notarial, Organización del Ministerio de Relaciones Exteriores, Síntesis del Derecho Civil y del Derecho Comercial y Derecho Diplomático (segunda parte).

Para el rango de Primer Secretario y Cónsul de Primera Clase: Geografía Política, Legislación Consular y Práctica Consular, Historia Diplomática del Paraguay (primera parte) y Organismos Internacionales.

Para el rango de Consejero y Cónsul General: Redacción y estilos de documentación diplomática, Nociones generales de Derecho Marítimo, Fluvial, Aéreo, Espacial y de Comunicaciones, Síntesis de Finanzas y Derecho Fiscal, Economía Política y Derecho Internacional Público. 
Para el rango de Ministro: Francés, Práctica Procesal Internacional, Comercio Internacional, Desarrollo e Integración, Derecho Político y Derecho Constitucional.

Para el rango de Embajador: Derecho Internacional Privado, Política Internacional y Geopolítica y Orientación de la Política Exterior Nacional.

A este plan inicial y bajo la dirección del entonces Ministro de Relaciones Exteriores, Embajador Alberto Nogués, se agregaron otras asignaturas. Así, el programa de estudios inicial abarcó dos años: el primero con once materias y el segundo con ocho. Desde la primera graduación ocurrida en 1979 hasta la promoción de 1999, egresaron 282 alumnos en total.

Las clases se desarrollaban en diferentes locales y con escasa regularidad, por la obligada ausencia de profesores y alumnos, debida a los viajes de servicio al exterior. Inicialmente, las clases se desarrollaron en el Palacio de Gobierno, sede de la Cancillería Nacional hasta 1975. En el transcurso del año lectivo de 1978, la Academia funcionó, en forma precaria y provisoriamente, en el edificio de la COPACAR (Corporación Paraguaya de Carnes), situado en las calles Presidente Franco y Juan E. O'Leary. Cabe advertir que, en esta etapa, varias embajadas acreditadas en el Paraguay, entre ellas las de Francia, Inglaterra, Chile y Brasil, otorgaban becas a los alumnos sobresalientes de la Academia; además, se recibieron libros sobre temas vinculados a las relaciones internacionales y a la diplomacia, material con el que se formó una incipiente biblioteca.

Después de ocupar las instalaciones de la COPACAR, la Academia tuvo otras seis localizaciones, hasta que en el año 2007 finalmente ocupa sede propia, en Humaitá y 14 de Mayo, conocida como la casona Gubetich.

A partir de la promulgación de las leyes No 1335 de 1999 y 1635 de 2000, se establecen los cursos que se desarrollarán para cada rango del Escalafón Diplomático y Consular:

Curso de Formación (para terceros secretarios),

Curso de Perfeccionamiento (para segundos y primeros secretarios), Curso de Actualización (para consejeros y ministros),

Si bien la malla curricular ha ido cambiando en estos 15 años, estos cursos se encuentran vigentes hasta el día de hoy.

En cuanto al nombre de la Academia, entre el 2008 y el 2013 tuvo la denominación de "Academia Diplomática y Consular José Falcón", en honor del primer Ministro de Relaciones Exteriores de la República.

En ocasión de la inauguración oficial de la actual sede, el 28 de febrero de 2013, se cambió la denominación de la Academia por la de "Carlos Antonio López", en homenaje a quien se considera el primer diplomático del país, ya que abrió el Paraguay a las principales potencias del mundo de ese entonces. Igualmente, la Biblioteca obtuvo la denominación de "Manuel Gondra", en reconocimiento a este canciller e intelectual paraguayo. 


\section{CONCURSO NACIONAL DE OPOSICIÓN Y MÉRITOS}

En el año 2007, siendo Ministro de Relaciones Exteriores el Embajador Rubén Ramírez, se inició el llamado nacional a Concurso de Oposición y Méritos, único camino para ingresar al Escalafón Diplomático y Consular, según lo establece la Ley 1335/99. A la convocatoria concurrieron en esa primera oportunidad 360 postulantes, de los cuales fueron seleccionados los 10 mejores, que ingresaron con el rango de tercer secretario.

Cabe destacar que el número de postulantes admitidos está dado por las vacancias de rubros disponibles para terceros secretarios, ya que no se podría permitir el ingreso de más funcionarios de los que el Presupuesto General de Gastos de la Nación asigna al Ministerio de Relaciones Exteriores para esa categoría.

Cuadro de Postulantes e Ingresantes al SDC paraguayo desde el establecimiento del Concurso Nacional de Oposición y Méritos ${ }^{5}$

\begin{tabular}{|c|c|c|c|c|}
\hline$N^{\circ}$ & Año & $\begin{array}{c}\text { Cantidad de } \\
\text { Postulantes }\end{array}$ & Plazas & Ingresantes \\
\hline I CONCURSO & 2007 & 286 & 10 & 10 \\
\hline II CONCURSO & 2009 & 332 & 10 & 10 \\
\hline III CONCURSO & 2010 & 254 & 15 & 15 \\
\hline IV CONCURSO & 2011 & 210 & 10 & 10 \\
\hline V CONCURSO & 2012 & 171 & 15 & 14 \\
\hline VI CONCURSO & 2013 & 209 & 15 & 15 \\
\hline VII CONCURSO & 2014 & 247 & 15 & 15 \\
\hline VIII & 2015 & 165 & 10 & 10 \\
CONCURSO & 2016 & 285 & 10 & 10 \\
\hline IX CONCURSO & Obs. En el año 2008 no se realizó el Concurso. \\
\hline
\end{tabular}

Cabe destacar que esta es la primera vez en la historia de la República del Paraguay que el ingreso al Servicio Diplomático y Consular se realiza exclusivamente a través de un Concurso Nacional de Oposición y Méritos durante un periodo sostenido de 10 años, habiendo pasado desde su implementación cuatro administraciones presidenciales de diferente signo político y seis Ministros de Relaciones Exteriores.

5 Fuente: Dirección General de la Academia Diplomática y Consular. Disponible en: $<$ http:// www.mre.gov.py/academiadiplomatica/institucional.html> 


\section{BASES JURÍDICAS ACTUALES DEL SERVICIO DIPLOMÁTICO Y CONSULAR DEL PARAGUAY}

\subsection{La Constitución Nacional}

La Ley suprema de la Nación Paraguaya consagra, en su artículo 143, los Principios de la su Política Exterior:

"La República del Paraguay, en sus relaciones internacionales, acepta el derecho internacional y se ajusta a los siguientes principios:

a) la independencia nacional;

b) la autodeterminación de los pueblos;

c) la igualdad jurídica entre los Estados;

d) la solidaridad y la cooperación internacional;

e) la protección internacional de los derechos humanos;

f) la libre navegación de los ríos internacionales;

g) la no intervención, y

h) la condena a toda forma de dictadura, colonialismo e imperialismo".

Asimismo, en el artículo 238, inciso 7 señala que una de las funciones del Presidente de la República es el manejo de las relaciones exteriores de la República.

Por otra parte, como ya se mencionó, la Carta Magna menciona a la carrera diplomática y consular en su artículo 101, en el cual establece que "Los funcionarios y los empleados públicos están al servicio del país. Todos los paraguayos tienen el derecho a ocupar funciones y empleos públicos. La ley reglamentará las distintas carreras en las cuales dichos funcionarios y empleados presten servicios, las que, sin perjuicio de otras, son la judicial, la docente, la diplomática y consular, la de investigación científica y tecnológica, la de servicio civil, la militar y la policial".

\subsection{Ley No 1335 de 1999 “Del Servicio Diplomático y Consular de la República del Paraguay” y modificaciones}

Esta es la ley que rige el ingreso, desempeño, evaluación y alcance de las funciones del Servicio Diplomático y Consular y establece la normativa fundamental del Escalafón Diplomático.

Asimismo, en el cuerpo de la ley se establecen las categorías (o rangos) del Escalafón, las disposiciones para el ingreso, ascenso, rotaciones y traslados, se señalan las condiciones para los nombramientos de funcionarios de fuera del Escalafón en el Servicio Exterior, se consigna una tabla de equiparación salarial entre rangos y cargos en el Ministerio de Relaciones Exteriores y se designa una Junta de Calificaciones responsable de la calificación anual de los funcionarios del Servicio, 
con miras a los correspondientes ascensos, rotaciones y traslados según corresponda, así como a la selección y propuesta de nuevos funcionarios para su ingreso al Escalafón. Asimismo, esta ley establece los cursos que debe organizar la Academia Diplomática y Consular para la permanente formación, perfeccionamiento y actualización de los miembros del Servicio, según los rangos. En cuanto al régimen disciplinario se remite a lo establecido para los funcionarios públicos en general.

Esta ley también establece los deberes, prohibiciones y derechos de los funcionarios del Servicio, con base en las normas del derecho internacional y los usos y prácticas diplomáticas generalmente reconocidos. Señala claramente las funciones del jefe de Misión Diplomática y estipula cláusulas para situaciones particulares como los destinos peligrosos, las situaciones familiares, la cobertura médica en el exterior, la muerte del funcionario en servicio, etc.

Se determina la reserva de ejercicio de la función consular para los funcionarios del Servicio Diplomático y Consular, sus deberes especiales y la posibilidad de designación de cónsules honorarios, con la expresa prohibición de actuar como oficiales públicos, visar, otorgar o revalidar pasaportes. En otro capítulo, se establecen las condiciones salariales, los gastos de instalación y viático, así como los de representación y mantenimiento de la sede de la Misión. Esta ley ha sido modificada por las siguientes leyes:

\subsubsection{Ley No 3943 de 2009 “Que modifica parcialmente el artículo 11 de la Ley No 1335 de 1999 "Del Servicio Diplomático y Consular de la República del Paraguay"}

Esta ley fue promulgada el 7 de diciembre de $2009^{6}$ y en su único artículo de fondo deroga lo establecido por el Numeral 5 del Inciso "e", del artículo 11 de la Ley No 1335 de 1999, que determina que para el ascenso de ministro a embajador se precisa "recibir el acuerdo del Senado de la República”.

Esta derogación está basada en la independencia de las decisiones de la Junta de Calificaciones en cuanto a los ascensos y, en particular, en la diferencia entre el ascenso a embajador (dentro del Escalafón) y la atribución presidencial de designar embajadores, con acuerdo del Senado, consagrada en el artículo 238 inciso 7 de la Constitución Nacional.

En el primer caso se trata de la asignación del más elevado rango dentro de la carrera diplomática y consular (aún si el candidato no fuera designado para ejercer como jefe de misión en un destino en el exterior), y en el segundo de la atribución presidencial de designar a sus representantes en el exterior, sean o no estos miembros del Servicio

6 Siendo Presidente de la República Fernando Lugo y Ministro de Relaciones Exteriores Héctor Lacognata. 
Diplomático y Consular.

\subsubsection{Ley No 4053 de 2010 "Que modifica los artículos $9^{\circ}$ y 14 de la Ley No 13351999 "Del Servicio Diplomático y Consular de la República del Paraguay"}

Esta ley fue promulgada el 2 de agosto de 2010 y realiza dos modificaciones, una en cada artículo de la Ley No 1335. En el artículo $9^{\circ}$ que versa sobre la posibilidad de designación "de embajador, a más de los funcionarios que ocupan dicha categoría en el Escalafón, a personas que, sin formar parte de él, posean notoria capacidad y versación para ocupar el cargo...", a esta redacción fue añadida la condición de que dicha persona debe contar con la nacionalidad paraguaya natural, por lo que el artículo quedó redactado "a más de los funcionarios que ocupan dicha categoría en el Escalafón, a personas de nacionalidad paraguaya natural que, sin formar parte de él, posean notoria capacidad y versación para ocupar el cargo...".

La segunda modificación consiste en el agregado del mes de abril como cita obligatoria para que la Junta de Calificaciones estudie la lista de ascensos y destinos, así como para elevar las listas resultantes de sus deliberaciones al Poder Ejecutivo para la realización de las rotaciones y traslados. En la versión original, la ley disponía que este estudio y la propuesta al Poder Ejecutivo se lleven a cabo sólo en el mes de octubre.

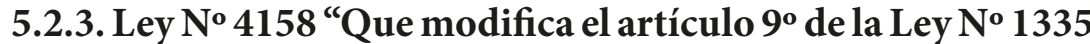 de 1999 "Del Servicio Diplomático y Consular de la República del Paraguay", modificado por la Ley No 4053 de 2010 "Que modifica los artículos 9० y 14 de la Ley No 1335 de 1999”}

Esta ley fue promulgada el 8 de noviembre de 2010 y agrega la condición de paraguayo "naturalizado" al candidato a embajador que no pertenezca al Servicio Diplomático y Consular. De esta forma, el artículo queda finalmente redactado (en su parte medular) de la siguiente manera: "El Presidente de la República, con acuerdo del Senado, podrá designar como embajador, a más de los funcionarios que ocupan dicha categoría en el Escalafón, a personas de nacionalidad paraguaya natural o naturalizada que, sin formar parte de él, posean notoria capacidad y versación para ocupar el cargo...".

\subsubsection{Ley No 4991 de 2013 "Que modifica el artículo 44 de la Ley No 1335 de 1999 "Del Servicio Diplomático y Consular de la República del Paraguay"}

Esta es la más reciente modificación de la Ley No 1335 de 1999, 
fue promulgada el 17 de julio de $2013^{7}$, y en la misma se amplía y especifica el alcance de lo dispuesto en el artículo 44, que versa sobre las remuneraciones de los funcionarios, tanto en el Servicio Local como en el Servicio Exterior.

Las modificaciones afectan a los funcionarios que prestan servicios en el exterior, de dos maneras: 1) se especifica no sólo que percibirán una remuneración en moneda extranjera, sino que esta tendrá una base común, por categoría. 2) se establece que estos, si correspondiera, percibirán además una remuneración adicional de hasta $50 \%$ de la remuneración respectiva, por diferencia de costo de vida.

A fin de establecer el porcentaje extra que podría percibir cada funcionario, dependiendo del costo de vida de la misión en la que se desempeña, esta ley establece que el Ministerio de Relaciones Exteriores deberá elaborar anualmente una tabla en la que se determine el índice de ajuste a ser aplicado para el cálculo de la remuneración adicional que corresponda a los funcionarios destinados a lugares con mayor costo de vida, de acuerdo a las estimaciones de organismos internacionales o empresas especializadas.

\subsubsection{Ley $1635 \mathrm{~N}^{\circ}$ de 2000 "Orgánica del Ministerio de Relaciones Exteriores"}

Promulgada el 18 de diciembre de 2000, siendo Presidente Luis Ángel González Macchi y Ministro de Relaciones Exteriores el Embajador Juan Esteban Aguirre, esta ley reafirma lo ya estipulado en la Constitución Nacional, que "El manejo de las relaciones exteriores de la República del Paraguay compete al Presidente de la República" y que El Ministerio de Relaciones Exteriores es el órgano que planifica, coordina y ejecuta la Política Exterior bajo la dirección del Presidente de la República".

A renglón seguido, estipula que "Todo órgano del Estado, cuando deba realizar alguna gestión de carácter oficial en el exterior, coordinará sus acciones con el Ministerio de Relaciones Exteriores" asignando, de esta manera, al Ministerio de Relaciones Exteriores la función de articulador de las políticas públicas entre los órganos del Estado y el exterior.

En esta ley, además de delimitar las funciones del Ministerio de Relaciones Exteriores en general y de la Cancillería en particular ${ }^{8}$, establece las funciones del Ministro, de las unidades dependientes directamente del Ministro, de los tres Viceministros y de sus Direcciones Generales dependientes; así también, delimita claramente la misión, el carácter y las funciones de las Misiones Diplomáticas, de las

7 Siendo Presidente de la República Federico Franco y Ministro de Relaciones Exteriores José Félix Fernández Estigarribia.

$8 \mathrm{La}$ diferencia entre ambos conceptos es que "Ministerio de Relaciones Exteriores" incluye a las misiones en el exterior, mientras que la "Cancillería" es sólo la sede central en Asunción. 
Representaciones Permanentes y de las Oficinas Consulares; delimita las funciones del Jefe de Misión, del Jefe de la Oficina Consular y de los Agregados Militares y Policiales. Por otra parte, la ley reitera lo ya establecido en el artículo 42 de la Ley No 1335 de 1999 de la reserva del ejercicio de la función consular para los funcionarios del Servicio Diplomático y Consular, salvo los casos de los cónsules honorarios, y reitera, asimismo, las inhabilidades de estos últimos.

Finalmente, detalla la conformación del plantel de funcionarios del Ministerio de Relaciones Exteriores, detalla la legislación por la cual se rige cada categoría de funcionario y establece un Escalafón administrativo, complementario al Escalafón diplomático y consular, destinado a profesionalizar y jerarquizar al personal administrativo del Ministerio de Relaciones Exteriores, equiparándoles, tanto en la posibilidad de prestar servicios en el exterior como en los beneficios que esto conlleva, a los diplomáticos escalafonados.

\section{EVOLUCIÓN DEL SERVICIO DIPLOMÁTICO Y CONSULAR, A PARTIR DE LA VIGENCIA DE LA LEY No 1335 DE 1999}

Considerando la gran trascendencia que tiene para la historia diplomática paraguaya la promulgación y vigencia ininterrumpida de esta ley, al cumplirse los 15 años de su implementación hemos realizado un estudio retrospectivo sobre la evolución del Escalafón Diplomático y Consular, que resumimos a continuación:

Primeramente realizaremos una comparación directa de la distribución de rangos entre el primer Escalafón, tal cual reza el Decreto No 6847 de 1999 y la situación a julio 2015:

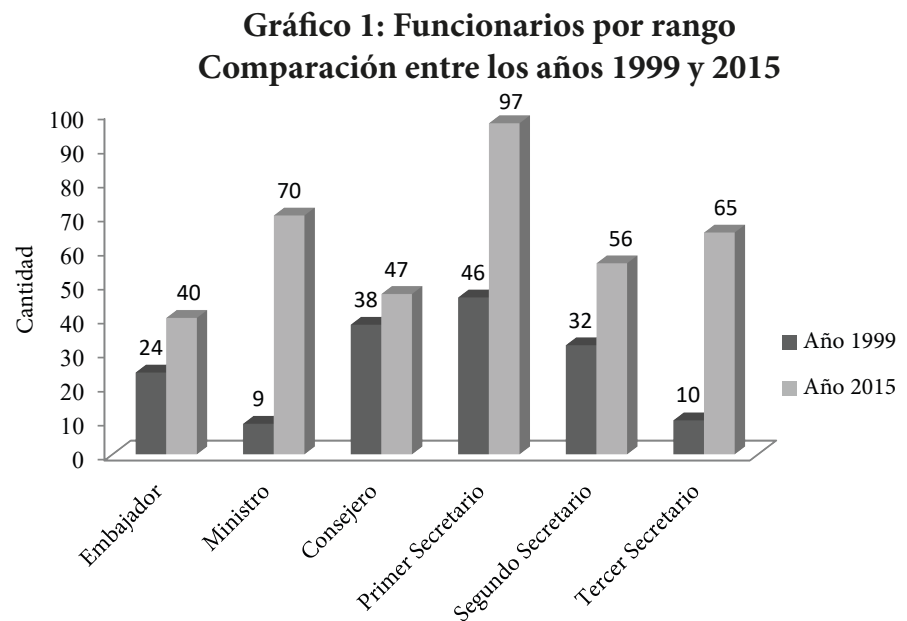

Fuente: Elaboración propia sobre la base del Archivo del MRE-PY. 2015. 
La categoría que ha tenido el mayor incremento es la de tercer secretario, producto principalmente de los Concursos que se vienen realizando desde el año 2007. En total, desde entonces, han ingresado 83 nuevos diplomáticos, y algunos de ellos ya han ascendido a segundo secretario, por lo que el número de 65 refleja las incorporaciones de los últimos años.

Si bien el número de funcionarios diplomáticos aumentó en todas las categorías, no hubo un significativo aumento de consejeros y se registró un moderado incremento entre los segundo secretarios; sin embargo, los otros dos rangos en los que se ha visto un importante incremento (luego de los terceros secretarios) son los de ministro y primer secretario, probablemente porque ambos son considerados como escalones previos a niveles de conducción de mucha mayor responsabilidad: consejero y embajador, respectivamente, por lo que los requisitos de ascenso son numerosos, según la Ley No 1335 de 1999, y más aún luego de la adopción del Reglamento de Calificación para funcionarios del Servicio Diplomático y Consular, en el año 2014. Este reglamento asigna una puntuación a cada mérito profesional, rasgo de idoneidad personal, rendimiento en servicio y años de antigüedad del funcionario, que se van sumando y son contabilizados anualmente por la Secretaría General, con información proveída por la Dirección de Recursos Humanos, con posibilidad de revisión por parte del funcionario.

Gráfico 2: Evolución de distribución de rangos en el periodo 1999-2015

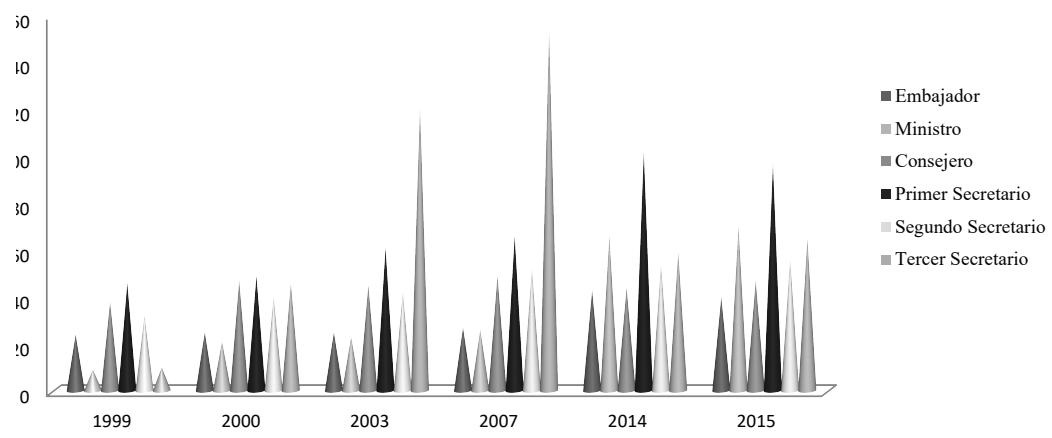

Fuente: Elaboración propia sobre la base del Archivo del MRE-PY. 2015.

Es importante recordar, asimismo, los periódicos ascensos determinados por la Junta de Calificaciones; esto significa que un funcionario que en el 1999 ocupaba el rango de segundo secretario (por ejemplo) a día de hoy probablemente sea consejero o ministro, dependiendo de los años de servicio, tanto en la Cancillería como en el exterior, de los cargos que haya ocupado en ese lapso y de los idiomas que hable; también podría estar en el rango de primer secretario, en 
caso de que no hable dos idiomas extranjeros, o no haya completado el Curso de Perfeccionamiento de la Academia Diplomática y Consular, o no se haya desempeñado por 4 años en el Servicio Exterior, ya que estos son requisitos para ascender a consejero.

Observando la evolución del número de funcionarios diplomáticos en cada rango del Escalafón, en estos últimos 15 años, tomando hitos puntuales, como el primer año de la promulgación de la Ley № 1335 de 1999 y el Decreto No 6847 de 1999, en el que se observa ya un importante aumento de los rangos de ministro y tercer secretario, particularmente de este último, que de los originales 10 (en 1999) pasó a 46 (en el año 2000); todas las incorporaciones en este primer año se dieron a través del Decreto 11.387, del 1 de diciembre del 2000, que hace lugar a los pedidos de reconsideración e incorpora a los funcionarios que los formularon, así como a los que estaban en la "lista de espera" del decreto original.

El siguiente corte es el año 2003, al inicio del periodo presidencial; aquí se observa un impresionante incremento en el número de Terceros Secretarios, que aumentó a 121, esto se debe a que en diciembre de 2002 se llevó a cabo el primer Concurso de Oposición y Méritos, mediante el cual ingresaron 41 nuevos terceros secretarios; asimismo, en esta cifra no se incluye a otros 6 terceros secretarios que ingresaron por un segundo concurso en diciembre de $2003^{9}$. Cabe destacar que estos primeros dos concursos estaban destinados sólo para funcionarios del Ministerio de Relaciones Exteriores, a diferencia de los que se iniciaron en el año 2007 que tienen carácter nacional. Además del importante aumento de los Terceros Secretarios, los demás rangos tuvieron escasa variación, salvo el de primer secretario, donde se aprecia la tendencia a la "acumulación" de funcionarios en este rango.

Seguidamente hemos observado la situación en el año 2007, incluyendo ya en la nómina a los 10 nuevos terceros secretarios que ingresaron mediante el Primer Concurso Nacional de Oposición y Méritos, así como los 6 mencionados en el párrafo anterior y otros 27 que la Junta de Calificaciones fue incorporando entre los años 2005 y 2007, ya sea en cumplimiento de órdenes judiciales u otros motivos que no constan en los registros. La suma de todas estas incorporaciones explica el nuevo record de aumento en esta categoría, sin parangón en las demás. El otro aumento de alguna consideración fue el de segundo secretario que aumentó de 42 a 52 .

Finalmente hemos realizado dos cortes con un año de diferencia entre ellos; el 2014, inicio de un periodo presidencial y el 2015. Entre el 2007 y el 2014 se aprecian interesantes diferencias, como el importante aumento en el número de ministros y embajadores y la drástica disminución de terceros secretarios que, sin embargo, curiosamente, no se refleja en un importante aumento de segundos secretarios, como se

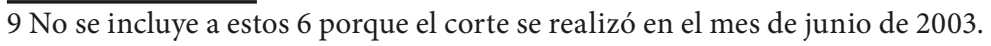


esperaría. El aumento de ministros trae aparejada una disminución en el número de consejeros, que guarda relación con el importante aumento del número de primeros secretarios, por el fenómeno ya mencionado más arriba. Dicho efecto, sin embargo, no se observa para el ascenso de ministro a embajador, ya que esta última categoría ha registrado un interesante aumento de 27 a 43 en este periodo (2007-2013).

En cuanto a la relación entre el 2014 y el 2015 cabe señalar que, si bien a simple vista aparentan tener las mismas cifras, cada categoría ha sufrido variaciones de un dígito, ya sea en aumento (ministro: de 66 subió a 70, consejero: de 44 subió a 47, segundo secretario: de 45 pasó a 56 y tercer secretario: de 59 subió a $65^{10}$ ) o en disminución (embajador: de 43 bajó a 40, primer secretario: de 102 bajó a 97), lo cual indica un año de moderado movimiento, si se considera la curva de evolución del Escalafón Diplomático y Consular, que se observa en el siguiente gráfico.

\section{Gráfico 3: Evolución de la cantidad total de funcionarios en el Escalafón Diplomático y Consular}

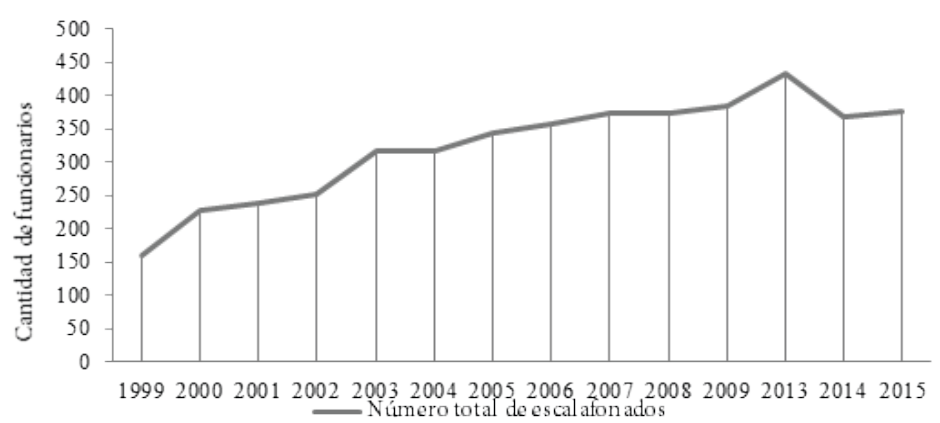

Fuente: Elaboración propia sobre la base del Archivo del MRE-PY. 2015.

\section{CONCLUSIÓN}

Luego de este análisis se puede concluir que este proceso de institucionalización en Paraguay es de largo aliento y que si bien ha comenzado a arrojar resultados positivos, los efectos estructurales podrán ser vistos a mediano plazo, una vez internalizada la mecánica competitiva de ingreso y ascensos, de mantenerse la tendencia de profesionalización y transparencia, y en caso de aplicarse permanentes medidas de evaluación, control y mejoramiento general del sistema, con el apoyo presupuestario del Gobierno central.

Habiendo revisado el proceso que ha seguido la República del

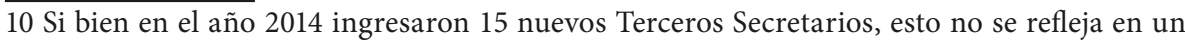
aumento automático por el ascenso de algunos Terceros a Segundos, ocurrido en el curso de este año. 
Paraguay, miembro fundador del MERCOSUR, para establecer y consolidar la profesionalización de su Servicio Diplomático y Consular, cabe preguntarse cuál es la incidencia de este hecho para el proceso de integración regional.

En este sentido, consideramos oportuno recordar que este proceso integrador no es un fin en sí mismo sino un instrumento para acceder al objetivo último: el crecimiento económico y la expansión de las oportunidades para la población de los Estados Miembros. De esta manera, la estabilidad y previsibilidad de esta carrera de servicio público, el arraigo del Servicio que traiga aparejada una mejor articulación entre políticas nacionales y hacia el exterior y, en suma, el fortalecimiento general de los respectivos Servicios Diplomáticos de sus Estados Miembros redunda, sin duda alguna, en una consolidación del proceso, ya que contribuye a la ejecución eficiente de las líneas de acción acordadas entre las Partes, reduce el nivel de improvisación en la gestión y aumenta así las posibilidades de avanzar sostenidamente en las políticas acordadas al más alto nivel.

Por ello, consideramos de suma importancia el proceso de institucionalización en marcha en la República del Paraguay y auguramos que el mismo no sea interrumpido ni retrasado ya que el MERCOSUR se construye y se afianza con la fortaleza de sus socios y, como dijera la Canciller de Paraguay, Embajadora Leila Rachid, en enero de 2005, en el lanzamiento de la Presidencia Pro-Témpore paraguaya: "Ya no hay tiempo que perder. La integración nos convoca a una presencia relevante en el mapa mundial. En la opacidad de los desencuentros solo seremos sombra en un mundo donde preciso es conquistar la dignidad humana".

\section{RESUMEN BIOGRÁFICO}

Liz Haydee Coronel Correa es Diplomática de carrera. Ministra en el Servicio Diplomático y Consular del Paraguay y autora del libro "El Servicio Diplomático y Consular del Paraguay. Historia y Proyección”. Asunción 2016. Magister en Planificación y Conducción Estratégica Nacional (IAEE 2015). Licenciada en Letras por la Universidad Nacional de Asunción.

\section{REFERENCIAS BIBLIOGRÁFICAS}

CIBILS WILSON-SMITH, Elianne. Compilación Concordada de Legislación Nacional e Internacional de uso del Ministerio de Relaciones Exteriores. Asunción: s.n, 2002. 249 p.

PARAGUAY. Constitución Nacional de la República Del Paraguay, 20 de junio de 1992.

PARAGUAY. Decreto No 24450, Que reglamenta la Ley No 219 “Que crea 
la Carrera Diplomática y Consular". 15 de febrero de 1972.

PARAGUAY. Decreto-Ley 14757, Que sustituye al Decreto-Ley 6430, referente al Estatuto Orgánico del Ministerio de Relaciones Exteriores y Culto, 24 de julio de 1946.

PARAGUAY. Ley No 1335 de 1999, Del Escalafón Diplomático y Consular, de 2 de marzo de 1999.

PARAGUAY. Ley No 1635 de 2000, Orgánica del Ministerio de Relaciones Exteriores, de 18 de diciembre de 2000.

PARAGUAY. Ley No 219, Que crea la Carrera Diplomática y Consular, 1 de diciembre de 1970.

PERALTA, Julio César. "15 años del Escalafón Diplomático y Consular". Revista Diplomática. Academia Diplomática y Consular. 2015, n 5, p. 79-87.

RACHID, Leila; RAMÍREZ, Rubén. Politica Exterior de la República del Paraguay. Herramienta para el desarrollo en un mundo globalizado. Memoria de gestión 2003-2008. Asunción: Ministerio de Relaciones Exteriores, 2008.

RAMÍREZ BOETTNER, Luis María. Sesenta y seis años de vida internacional. Asuncion: Intercontinental Editora, 2010. 